\title{
QUIROPTEROS DE LONDRINA, PARANÁ, BRASIL (MAMMALIA, CHIROPTERA)
}

\author{
Nélio Roberto dos Reis 1 \\ Adriano L. Peracchi ${ }^{2}$ \\ Maria K. Onuki ${ }^{1}$
}

\begin{abstract}
CHIROPTERUS OF LONDRINA, PARANÁ, BRAZIL (MAMMALIA, CHIROPTERA). Due to the lack of information concerning mammals in the North of Paraná State, Brazil. a preliminary survey of bat species of the region of Londrina is presented. Three hundred and thirty four individuals of 18 species belonging to Phyllostomidae, Desmodontidae, Vespertilionidae and Molossidae families were collected. Data were gathered related to threir feeding habits, reproduction and time of achvity.

KEY WORDS. Mammalia, Chiroptera, Londrina, Paraná, Brazil
\end{abstract}

A região do norte do Estado do Paraná outrora era ŕecoberta por floresta subtropical densa, que abrigava uma grande diversidade de plantas e animais. Com a explosiva ampliação da atividade agrícola, mormente da lavoura cafeeira, que se verificou na região, principalmente de 1870 à 1950 , em virtude da fertilidade das terras, mais de $90 \%$ desse valioso ecossistema foi destruído, sem que houvesse preocupação com alguma forma de conservação ou preservação. A destruição total desse ecossistema só não se completou porque restaram alguns remanescentes, formando verdadeiras ilhas, circundadas por áreas de intensa exploração agrícola.

Face a escassez de informações sobre os mamíferos da região, apresentamos um levantamento preliminar das espécies de quirópteros que ocorrem no município de Londrina, fornecendo dados sobre hábitos alimentares, horário de atividades e reprodução de algumas espécies.

\section{MATERIAL E MÉTODOS}

O município de Londrina está situado a $23^{\circ} 23^{\prime} 30^{\prime \prime} \mathrm{W}$ e $51^{\circ} 11^{\prime} 5^{\prime \prime} \mathrm{S}$ e tem uma altitude média de $600 \mathrm{~m}$. Possui clima subtropical úmido, com temperatura média anual oscilando entre 22 e $25^{\circ} \mathrm{C}$, sendo fevereiro o mês mais quente do ano, com temperatura média entre 26 e $28^{\circ} \mathrm{C}$ e julho, o mais frio, com 15 a $17^{\circ} \mathrm{C}$. O índice pluviométrico anual está em torno de $1500 \mathrm{~mm}$, sendo os meses mais

1) Departamento de Biologial Animal e Vegetal, Fundação Universidade Estadual de Londrina, Caixa Postal 6001, 80051-970 Londrina, Paraná, Brasil.

2) Instituto de Biologia, Universidade Federal Rural do Rio de Janeiro, Caixa Postal 74584, 23851-970 Itaguaí, Rio de Janeiro, Brasil. 
chuvosos dezembro, janeiro e fevereiro (com médias pluviométricas de 500 a $550 \mathrm{~mm}$ ) e os meses mais secos os de junho, julho e agosto, com 200, 250 e $300 \mathrm{~mm}$, respectivamente.

Os trabalhos de campo foram desenvolvidos de janeiro de 1982 a novembro de 1983, tendo sido escolhidas cinco estações de coletas (fig. 1), a saber:

1. Parque Estadual Mata do Godoy. Um dos mais importantes remanescentes da biota local, vez que foi preservado desde que a região começou a ser desbravada em 1930, constituindo-se, inicialmente, na Reversa da Fazenda Santa Helena, dos irmãos Godoy, sendo recentemente adquirida pelo Governo do Estado do Paraná e transformada em Parque Estadual. Conta com uma área de 680 hectares e altitude média de 700m. Cortado pelo Trópico de Capricórnio, apresenta temperatura média anual de $20,7^{\circ} \mathrm{C}$ e média pluviométrica anual de $1250 \mathrm{~mm}$, com períodos mais úmidos de novembro a março e períodos mais secos, de abril a outubro. O Ribeirão Apertados é o único curso d'água perene do Parque e margeia seu lado sul. Existem córregos intermitentes após chuvas fortes, bem como algumas minas d'água nos vales mais íngremes. A metade norte do Parque é relativamente uma planície sem água corrente; a metade sul é composta por cinco colinas paralelas, com declive moderado. Uma floresta densa subtropical, relativamente alta, recobre quase toda a extensão do Parque, exceto nas áreas com declives relativamente íngremes, onde crescem poucas árvores, mas onde existe grande quantidade de bambu. A floresta é basicamente latifoliar, com cerca de $20 \%$ de espécies decíduas e a altura média de $25 \mathrm{~m}$, com árvores emergentes de 35 a 40m. Há grande quantidade de trepadeiras e cipós e um crescimento moderado de epífitas. As árvores mais importantes são "peroba" (Aspidosperma polyneuron), "figueiras" (Ficus sp.), "cedro" (Cedrela sp.), "pau marfim" (Balfourodendron sp.), "imbiuva" (Hymenaea sp.), "araribá" (Centrolobium sp.), "cabriuva" (Myroxylon sp.), "jacarandá pardo" (Dalbergia sp.), "imbuia" (Phoebe sp.), "tabebuia" (Tabebuia sp.), "pau d'alho" (Galesia sp.) e as palmeiras mais comuns, "palmito" (Euterpe edulis) e Arecastrum sp. Moráceas, solanáceas e piperáceas são comuns nas margens da mata.

2. Parque Arthur Thomas. Parque municipal, com área de 86 hectares, localizado na periferia da cidade de Londrina, às margens da Avenida Dez de Dezembro (Via Expressa), na altura do Jardim Piza. Nessa área situava-se a antiga usina hidroelétrica da cidade e até hoje se mantém um pequeno zoológico com animais regionais. Existe na área pequeno lago artificial, formado pelo Ribeirão Cambé e lá ainda se encontram as casas de máquinas, abandonadas, da antiga hidroelétrica. Pequena colônia, de moradores permanentes, está instalada no local, que ainda apresenta remanescentes da floresta típica do norte do Paraná.

3. Campus da Universidade Estadual de Londrina. Localizado no $\mathrm{Km}$ 379 da Rodovia Celso Garcia Cid, dista aproximadamente $5 \mathrm{~km}$ do centro da cidade e conta com área de 230 hectares. A área do campus onde foram realizadas as coletas é constituída em sua maior extensão por gramados, com árvores esparsas, representadas, principalmente, por "perobas", "figueiras", "sibipirunas" (Caesalpinea peltophoroides), "castanheiras" (Terminalia catapa), 


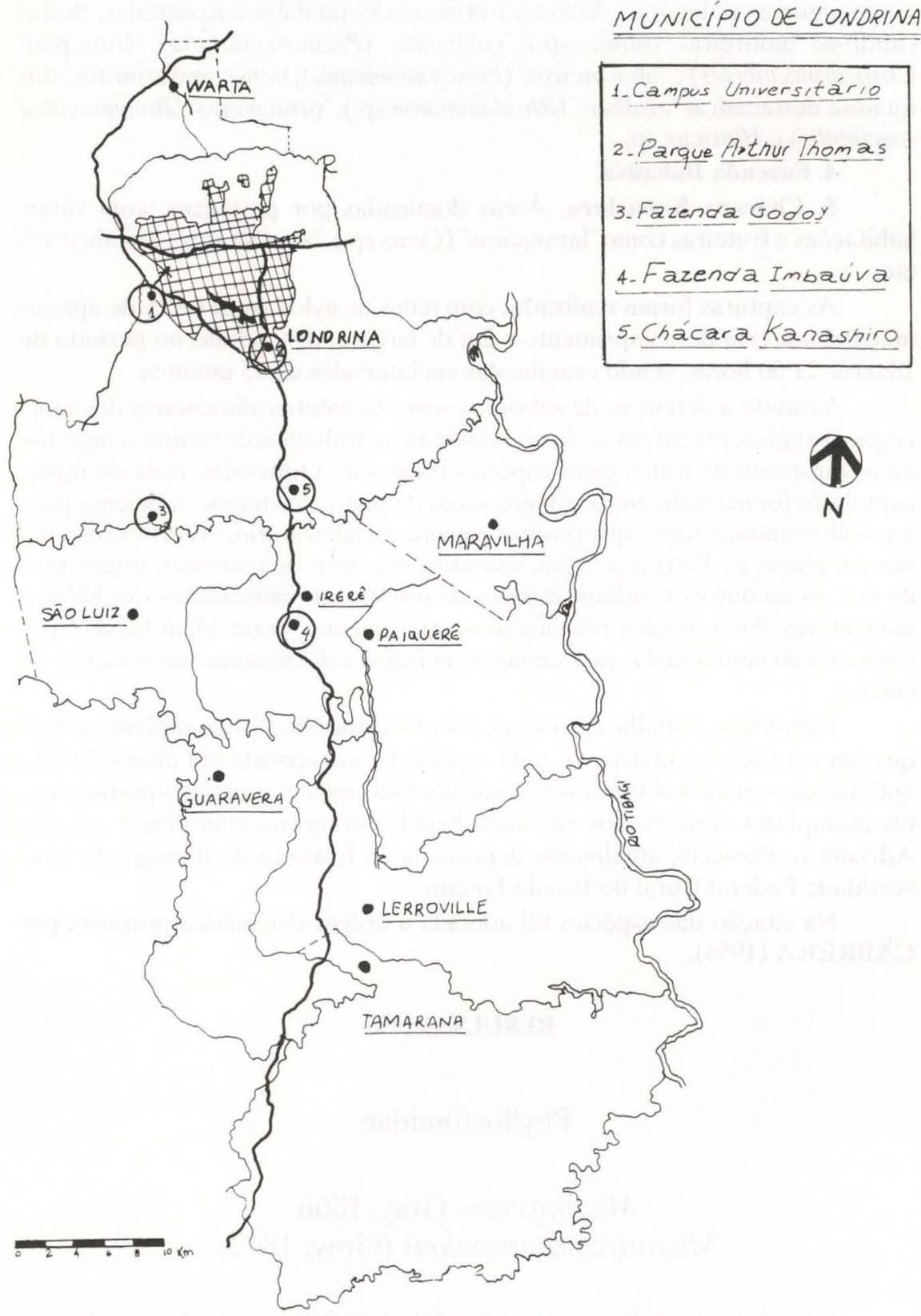

Fig. 1. Estações de coleta no município de Londrina. 
"bisnagueiras" (Spathodea campanulata), várias espécies do gênero Cassia e ainda algumas palmeiras. Árvores frutíferas são também encontradas, destacando-se "amoreiras" (Morus sp.), "goiabeiras" (Psidium guayaba), "fruta pão" (Artocarpus incisus) e "abacateiros" (Persea americana), bem como arbustos, dos quais se destacam as "azaléias" (Rhododendron sp.), "primaveras" (Bougainvillea spectabilis) e Hibiscus sp.

\title{
4. Fazenda Imbaúva.
}

5. Chácara Kanashiro. Áreas dominadas por pastagens, com várias habitações e fruteiras como "laranjeiras" (Citrus sp.), "abacateiros", "goiabeiras", etc.

As capturas foram realizadas com redes de nylon (mist nets), de aproximadamente $18 \mathrm{~m}$ de comprimento e $2 \mathrm{~m}$ de largura, distendidas no período de 18:00 às 21:00 horas, sendo examinadas em intervalos de 15 minutos.

Visando a obtenção de subsídios sobre os hábitos alimentares dos morcegos da região, procuramos observar durante os trabalhos de campo, a ingestão ou o transporte de frutos pelas espécies frugívoras. Outrossim, cada exemplar capturado foi mantido em pequenos sacos de pano, por tempo suficiente para o recolhimento de fezes, que posteriormente, no laboratório, eram desmanchadas em placas de Petri com água, visando o encontro de sementes, fragmentos de insetos ou outros resíduos, capazes de servir como indicadores dos hábitos alimentares das espécies relacionadas. As sementes eram identificadas por comparação com aquelas provenientes de frutos colecionados nas estações de coletas.

Durante os trabalhos de campo foram capturados 334 exemplares, sendo que amostra representativa de cada espécie foi conservada em álcool $70^{\circ} \mathrm{GL}$, após fixação em formol $10 \%$ e o restante liberado após as anotações pertinentes. Os exemplares conservados em meio líquido foram incorporados à coleção Adriano L. Peracchi, atualmente depositada no Instituto de Biologia da Universidade Federal Rural do Rio de Janeiro.

Na citação das espécies foi adotada a ordem sistemática proposta por CABRERA (1958).

\section{RESULTADOS}

\author{
Phyllostomidae
}

\author{
Micronycteris Gray, 1866 \\ Micronycteris megalotis (Gray, 1842)
}

Um único exemplar dessa espécie foi capturado no mês de setembro no Parque Arthur Thomas e apresentava fragmentos de insetos nas fezes.

Material examinado. Um macho, Parque Arthur Thomas, 10-IX-83. 


\section{Phyllostomus Lacépède, 1799 Phyllostomus hastatus (Pallas, 1767)}

Um macho dessa espécie foi capturado no mês de abril, bem como quatro fêmeas em maio, todos no Parque Arthur Thomas e apresentavam fragmentos de insetos e resto de frutos nas fezes.

Material examinado. Cinco exemplares: um macho e quatro fêmeas. Um macho, Parque Arthur Thomas, 13-IV-83 e quatro fêmeas, Parque Arthur Thomas, 14-V-83.

\section{Chrotopterus Peters, 1865 Chrotopterus auritus (Peters, 1856)}

Uma fêmea foi colecionada no Parque Estadual Mata do Godoy em março, enquanto uma fêmea e um macho foram obtidos no Parque Arthur Thomas, nos meses de setembro e novembro, respectivamente e em suas fezes foram encontrados fragmentos de insetos.

Material examinado. Três exemplares: um macho e duas fêmeas. Uma fêmea, Parque Estadual Mata do Godoy, 23-III-82; uma fêmea, 24-IX-83, um macho, 06-XI-83, Parque Arthur Thomas.

\section{Glossophaga E. Geoffroy, 1818 Glossophaga soricina (Pallas, 1766)}

Um exemplar dessa espécie nectarívora foi colecionado em março no Parque Estadual Mata do Godoy.

Material examinado. Uma fêmea, Parque Estadual Mata do Godoy, 23-III-82.

\section{Carollia Gray, 1838 \\ Carollia perspicillata (L., 1758)}

É uma das espécies mais freqüentes na região. Uma fêmea e um macho juvenis foram colecionados no Parque Estadual Mata do Godoy, em fevereiro e março, respectivamente. A maioria dos exemplares capturados eliminaram, nas fezes, sementes de Piper aduncum e de outra espécie não determinada de Piper, indicando que Piperáceas constituem, também nessa região, importante recurso alimentar para esses quirópteros.

Material examinado. 20 exemplares: nove fêmeas e 11 machos. Uma fêmea juvenil, Parque Estadual Mata do Godoy, 12-II-82; um macho juvenil e três machos, idem, 23-III-82; quatro fêmeas e quatro machos, idem, 17-V-82; um macho, idem, 05-XI-82; duas fêmeas, Parque Arthur Thomas 12-IV-83; uma fêmea, idem, 10-IX-83; um fêmea, idem, 24-IX-83; um macho, idem, 05-XI-83. 


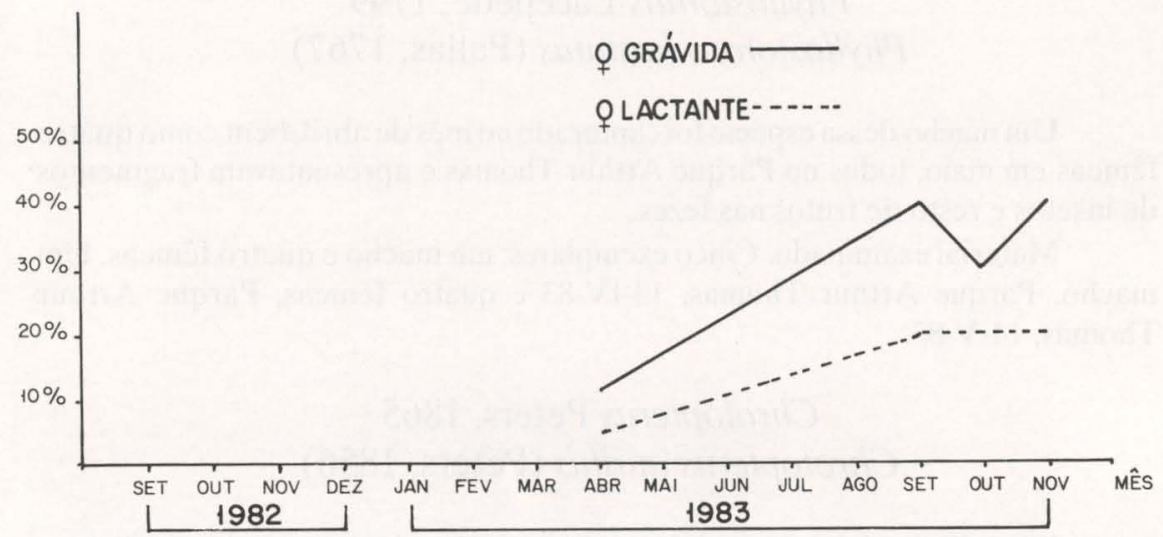

Fig. 2. Gráfico do ciclo reprodutivo de Sturnira lilium na região de Londrina.

\section{Sturnira Gray, 1842 Sturnira lilium (E. Geoffroy, 1810)}

Espécie muito freqüente na região, tendo sido capturados 27 machos e 42 fêmeas. Uma fêmea grávida foi capturada em janeiro, na Chácara Kanashiro e uma fêmea grávida e outra lactante foram colecionadas no Parque Estadual Mata do Godoy, no mês de março. No mês de abril, foram colecionadas oito fêmeas no Parque Arthur Thomas, sendo que destas, uma estava grávida e outra era lactante. De 10 fêmeas obtidas em setembro no Parque Arthur Thomas, três estavam grávidas e uma era lactante. No mês de outubro, quatro fêmeas grávidas foram colecionadas naquele Parque e em novembro, duas fêmeas grávidas foram capturadas na mesma estação. Na figura 2 apresenta-se gráfico do ciclo reprodutivo de Sturnira lilium na região estudada. Vários exemplares dessa espécie eliminaram, nas fezes, sementes de Piper aduncum, Piper sp., Ficus sp., Cecropia sp., Passiflora sp., Solanum sp. e de Solanácea não identificada.

Material examinado. 69 exemplares: 42 fêmeas e 27 machos. Uma fêmea grávida, uma fêmea lact., dois machos, Parque Estadual Mata do Godoy, 23-III-82; uma fêmea e quatro machos, idem, 17-V-82; uma fêmea grávida, Chácara Kanashiro, 20-I-83; três fêmeas e três machos, Campus Universidade Estadual de Londrina (UEL), 08-III-83; quatro fêmeas e quatro machos, Parque Arthur Thomas, 09-III-83; quatro fêmeas e três machos, Campus UEL, 05-IV83; uma fêmea, Parque Arthur Thomas, 09-IV-83; uma fêmea lact., duas fêmeas e um macho, idem, 12-IV-83; uma fêmea grávida e um macho, idem, 13-IV-83; três fêmeas e dois machos, idem 16-IV-83; duas fêmeas, idem, 14-V-83; uma fêmea lact., três fêmeas grávidas e uma fêmea, idem, 10-IX-83; um fêmea grávida, quatro fêmeas e dois machos, idem, 24-IX-83; quatro fêmeas grávidas, cinco machos, idem, 08-X-83; duas fêmeas grávidas, um macho, idem, 05-XI-83; um macho, idem 06-XI-83; uma fêmea, idem, 07-XI-83. 


\section{Platyrrhinus Saussure, 1860 Platyrrhinus lineatus (E. Geoffroy, 1810)}

Essa espécie, só foi colecionada no campus da Universidade Estadual de Londrina. Exemplares foram capturados em maio, agosto, setembro e outubro. Nas fezes de sete indivíduos foram encontradas sementes de Ficus, em um sementes de Cecropia, enquanto em outro havia sementes de Ficus e Cecropia.

Material examinado. 11 exemplares: seis fêmeas e cinco machos. Um macho, Campus da UEL, 16-IX-82; um macho, idem, 28-IX-82; um macho, idem, 14-X-82; duas fêmeas, idem, 02-V-83; duas fêmeas e dois machos, idem, 04-V-83; duas fêmeas, idem, 27-VIII-83.

\section{Artibeus Leach, 1821 Artibeus jamaicensis Leach, 1821}

Dois exemplares dessa espécie, pouco freqüente na região, foram colecionados em novembro no Parque Estadual Mata do Godoy. Nas fezes de um deles foram encontradas sementes de Ficus sp.

Material examinado. Dois exemplares: uma fêmea e um macho. Uma fêmea, Parque Estadual Mata do Godoy, 23-III-82; um macho, idem 05-XI-82.

\section{Artibeus lituratus (Olfers, 1818)}

Dessa espécie, a mais comum na região, foram capturados 200 exemplares. Um macho juvenil foi capturado no Parque Estadual Mata do Godoy em março, enquanto uma fêmea lactante foi obtida no campus da Universidade Estadual de Londrina e, no Parque Arthur Thomas, de quatro fêmeas colecionadas, uma estava grávida e outra era lactante. No mês de abril, uma fêmea lactante foi obtida no campus da Universidade, enquanto que no Parque Arthur Thomas, de 11 fêmeas capturadas, duas estavam grávidas e uma era lactante. Nessa última estação, no mesmo mês, de 14 machos capturados, dois eram juvenis. De três fêmeas obtidas no Parque Arthur Thomas, em maio, uma estava grávida e outra era lactante, enquanto, no campus da Universidade, de 18 fêmeas colecionadas, cinco eram lactantes e sete estavam grávidas. Cinco fêmeas capturadas no campus da Universidade, em agosto, estavam grávidas. De 18 fêmeas colecionadas no Parque Arthur Thomas, em setembro, 12 estavam grávidas e três eram lactantes, enquanto no campus da Universidade, de oito fêmeas capturadas, cinco estavam grávidas. Duas fêmeas grávidas e uma lactante foram obtidas no campus da Universidade em outubro, enquanto no Parque Arthur Thomas de nove fêmeas capturadas, sete estavam grávidas e uma era lactante. Um macho juvenil foi obtido no Parque Estadual Mata do Godoy em novembro, enquanto no Parque Arthur Thomas foram colecionadas 12 fêmeas lactantes e no campus da Universidade, 16 fêmeas capturadas, nove estavam grávidas e sete eram lactantes. Nas fezes dos exemplares colecionados 
encontramos, com freqüência elevada, sementes de Cecropia e Ficus e, com menor freqüência, sementes de Solanum sp, Piper sp e Morus sp (amoreira). Na figura 3 apresenta-se gráfico relativo ao ciclo reprodutivo dessa espécie na região estudada.

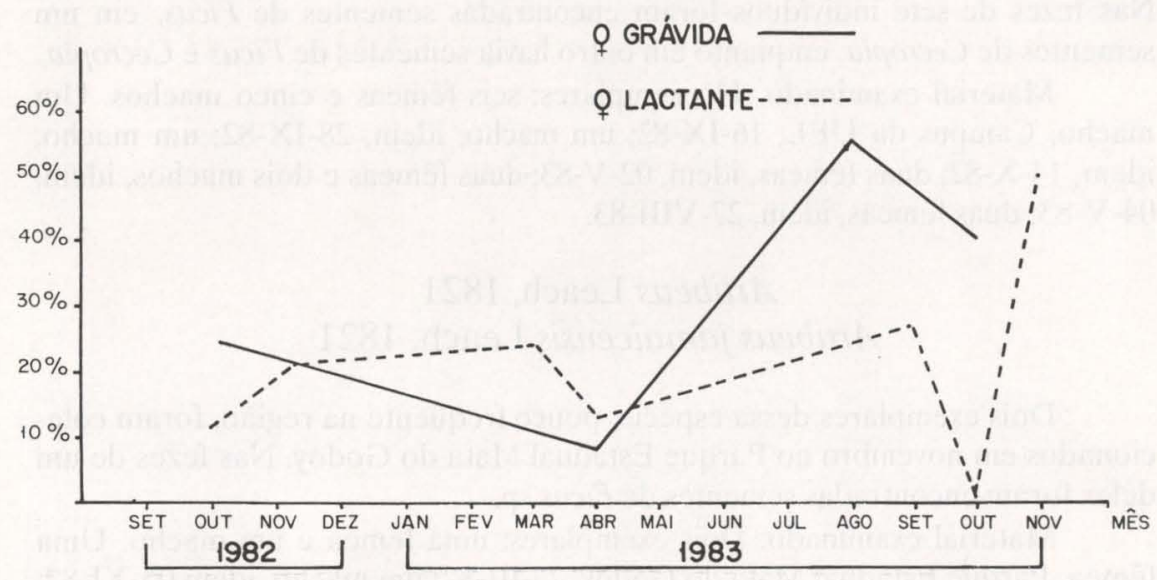

Fig. 3. Gráfico do ciclo reprodutivo de Artibeus lituratus na região de Londrina.

Material examinado. 200 exemplares: 111 fêmeas e 89 machos. Um macho juvenil, Parque Estadual Mata do Godoy, 23-III-82; três fêmeas, duas fêmeas grávidas e quatro machos, Campus UEL, 16-IX-82; dois machos, idem, 26-IX-82; três fêmas grávidas e dois machos, idem, 28-IX-82; uma fêmea lact., duas fêmeas, grávidas e cinco machos, idem, 14-X-82; um macho, Parque Estadual Mata do Godoy 05-XI-82; nove fêmeas grávidas, sete fêmeas lact. e 17 machos, Campus UEL, 18-XI-82; um macho, Chácara Kanashiro, 23-I-83; uma fêmea lact. e um macho, Campus UEL, 08-III-83; uma fêmea grávida, uma fêmea lact., duas fêmeas e três machos, Parque Arthur Thomas 09-III-83; uma fêma lact. e dois machos, Campus UEL, 05-IV-83; três fêmeas, uma fêmea grávida e cinco machos, Parque Arthur Thomas 09-IV-83; uma fêmea grávida, uma fêmea lact., três fêmeas, dois machos juvenis e um macho, idem, 12-IV-83; uma fêmea e três machos, 13-IV-83; uma fêmea lact., duas fêmeas e um macho, idem, 16-IV-83; três machos, Fazenda Imbauva, 01-V-83; três fêmeas lact., quatro fêmeas grávidas, cinco fêmeas e 10 machos, Campus UEL, 02-V-83; uma fêmea lact., idem, 03-V-83; duas fêmeas grávidas, uma fêmea lact. e dois machos, idem, 04-V-83; uma fêmea grávida, idem, 08-V-83; um fêmea, idem, 10-V-83; uma fêmea lact., uma fêmea grávida, uma fêmea e um macho, Parque Arthur Thomas, 14-V-83; cinco fêmeas grávidas e dois machos, Campus UEL, 27-VIII83; seis fêmeas grávidas, três fêmeas lact. e duas fêmeas, Parque Arthur Thomas, 10-IX-83; seis fêmeas grávidas, um fêmea e três machos, idem, 24-IX-83; sete fêmeas grávidas, uma fêmea lact., uma fêmea e 10 machos, idem, 08-X-83; quatro fêmeas lact. e dois machos, idem, 05-XI-83; cinco fêmeas lact. e um 
macho, idem, 06-XI-83; três fêmeas lact. e um macho, idem, 07-XI-83; dois machos e um macho juvenil, Parque Estadual Mata do Godoy, 15-XI-83.

\title{
Pygoderma Peters, 1863 \\ Pygoderma bilabiatum (Wagner, 1843)
}

Um único exemplar dessa espécie foi colecionado em novembro, no Parque Arthur Thomas.

Material examinado. Um macho, Parque Arthur Thomas, 05-XI-83.

\section{Desmodontidae}

\section{Desmodus Wied, 1826 \\ Desmodus rotundus (E. Geoffroy, 1810)}

Um exemplar dessa espécie de vampiro foi colecionado no município de Sertanópolis, próximo ao de Londrina, na fazenda Regina, em rede japonesa armada num trecho de aproximadamente 2,5 alqueires de mata primitiva ainda existente naquela propriedade. Dada a extensa distribuição geográfica dessa espécie, certamente ela ocorre, também, no município de Londrina e coletas com redes armadas nas proximidades de cocheiras e estábulos certamente confirmarão essa ocorrência. data.

Material examinado. Um macho, Fazenda Regina, Sertanópolis, sem

\section{Vespertilionidae}

\author{
Myotis Kaup, 1829 \\ Myotis ruber (E. Geoffroy, 1806)
}

Um único exemplar dessa espécie insetívora, uma fêmea lactante, foi colecionada no Parque Estadual Mata do Godoy, em novembro.

Material examinado. Uma fêmea lact., Parque Estadual Mata do Godoy, 05-XI-83.

\section{Eptesicus Rafinesque, 1820 Eptesicus brasiliensis (Desmarest, 1819)}

Um macho e uma fêmea dessa espécie insetívora foram capturados em novembro, no Parque Estadual Mata do Godoy. Outro exemplar, um macho, foi colecionado na mesma estação, em março, enquanto uma fêmea foi capturada na Fazenda Imbaúva, em maio.

Material examinado. Quatro exemplares: duas fêmeas e dois machos. 
Uma fêmea e um macho, Parque Estadual Mata do Godoy, 05-XI-82; um macho, idem, 25-III-83; uma fêmea, Fazenda Imbaúva, 01-V-83.

\section{Molossidae}

\section{Molossus E. Geoffroy, 1805 Molossus molossus (Pallas, 1766)}

Cinco exemplares desse morcego insetívoro foram colecionados no Campus da Universidade Estadual de Londrina.

Material examinado. Cinco exemplares macho. Um macho, Campus UEL, II-82; três machos, idem, VII-83; um macho, idem, X-83.

\section{Molossus ater E. Geoffroy, 1805}

Trabalhos de campo conduzidos no campus da Unversidade Estadual de Londrina permitiram capturar quatro exemplares desse morcego insetívoro, sendo três fêmeas e um macho.

Material examinado. Quatro exemplares: três fêmeas e um macho, Campus UEL, 1982.

$$
\begin{gathered}
\text { Nyctinomops Miller, } 1902 \\
\text { Nyctinomops laticaudatus (E. Geoffroy, 1805) }
\end{gathered}
$$
julho.

Um macho foi colecionado no centro da cidade de Londrina, no mês de

Material examinado. Um macho, cidade, Londrina, VII-83.

\section{Tadarida Rafinesque, 1814 Tadarida brasiliensis (I. Geoffroy, 1824)}

Um exemplar, macho, foi encontrado morto, num edifício no centro da cidade de Londrina.

Material examinado. Um macho, cidade, Londrina, 1982.

$$
\begin{gathered}
\text { Molossops Peters, } 1865 \\
\text { Molossops abrasus (Temminck, 1827) }
\end{gathered}
$$

Cinco fêmeas e dois machos dessa espécie foram encontrados no ôco existente numa "peroba" que tombou no campus da Universidade Estadual de Londrina.

Material examinado. Sete exemplares: cinco fêmeas e dois machos, Campus UEL, IX-83. 


\section{REFERÊNCIAS BIBLIOGRÁFICAS}

Cabrera, A. 1958. Catálogo de los mamiferos de America del Sur. Rev. Mus. Argent. Cienc. Nat. Zool. 4 (1): XVI + 307.

Recebido em 26.I.1991; aceito em 25.XI.1993. 